Departamento de Psiquiatría Escuela de Medicina,

Universidad de Valparaíso.

Recibido el 25 de abril de 2014 aceptado el 10 de septiembre de 2014.

Correspondencia a: Gustavo Figueroa gfigueroacave@gmail.com

\section{El médico virtuoso en el cine: el examen final}

\author{
GUSTAVO FIGUEROA
}

\section{The virtuous doctor in cinema: the final examination}

\begin{abstract}
The virtuous doctor has subscribed an oath and by subscribing to this solemn promise, he is committed to live in accordance with the purposes, obligations and virtues established in the medical profession. Cinematic art has shown only a superficial interest in complex aspects of medical profession. An exception is Ingmar Bergman's film "Wild Strawberries", where Professor Isak Borg, a widowed 76-year-old physician, is to be awarded the Doctor Jubilaris degree, 50 years after he received his doctorate at Lund University. During the trip, Isak is forced by a nightmare to reevaluate his professional life as not being a virtuous doctor.

(Rev Med Chile 2014; 142: 1324-1329)
\end{abstract}

Key words: Bioethics; Ethicists; Films; Medicine, motion picture.
E 1 médico virtuoso ha suscrito un juramento y por suscribir esta promesa solemne, él está comprometido a vivir en concordancia con los propósitos, obligaciones y virtudes establecidas en la profesión médica. El arte cinematográfico ha mostrado un interés pasajero en los aspectos más complejos de la medicina. Una excepción la constituye la película de Ingmar Bergman "Fresas salvajes”, donde el profesor Isak Borg, un médico viudo de 76 años, se le va a nombrar doctor honoris causa después de 50 años de recibir su doctorado por la Universidad de Lund. Durante su viaje Isak es forzado, a causa de una pesadilla, a reevaluar su vida profesional como no siendo la de un doctor virtuoso.

Desde los albores de Occidente han existido tres profesiones esenciales: sacerdotes, monarcas y médicos, quizás porque todas suponen un compromiso solemne de carácter sagrado, como atestigua el Juramento hipocrático ${ }^{1-3}$. Por ello el médico ha tenido que ejecutar bien no sólo sus técnicas sino además profesar una moral que tiende a la excelencia (areté) y ya Aristóteles habla del "médico perfecto" y Galeno del "óptimo médico"s. Contrariamente, la actual medicina hipertecnificada ha privilegiado ostensiblemente los conocimientos, habilidades y destrezas evaluadas según las últimas evidencias objetivas ${ }^{6}$; esta objetivización e instrumentalización han conducido a cuestionamientos provenientes tanto de médicos como pacientes y sociedad: deshumanización ${ }^{7,8}$, confusión sobre metas ${ }^{9}$, medicalización extrema$\mathrm{da}^{10}$, judicalización y utopías desenfrenadas ${ }^{11,12}$. Así, ha descuidado las virtudes del médico y valores de la profesión ${ }^{13}$, obligándolo a "bien hacer" antes que "hacer bien", a los "derechos y deberes" antes que "las virtudes", a la virtuosidad técnica antes que la persona virtuosa. Ahora resulta lícito aplicar las palabras de MacIntyre: médicamente vivimos "después" de la virtud, after virtue, razón por la cual es urgente ir "tras" ella, after virtue ${ }^{14}$.

Por otra parte, Heidegger ha advertido que Occidente ha "agotado sus posibilidades" ${ }^{15} y$ Rorty afirma que es el artista, más que el filósofo, el que aprehende mejor la realidad en nuestra época ${ }^{16}$. Es que el arte, agudamente agregó Heidegger, des-cubre (Ent-deckung) la realidad, pero no trata de traducir en lenguaje técnico el significado supuestamente "profundo" o "verdadero" de una obra, sino de meditar (Besinnen) a propósito de las señales (Winke) que envía sobre lo que es ser hombre [médico], para examinarlo "con nuevos ojos y con preguntas más auténticas" ${ }^{17}$.

El arte del cine ha mostrado los médicos y la 
medicina desde diferentes perspectivas dependiendo de los supuestos, metas e ideologías de sus realizadores ${ }^{18-21}$. La creatividad de los cineastas ha penetrado, en ocasiones, al interior de la profesión con una riqueza y sutileza que iguala a la de otras artes, aún proporciona una visión que no se consigue con las restantes. El presente trabajo intenta estudiar el bios iatrikós ${ }^{22,23}$, el modo de vida propio del médico virtuoso según se muestra en el cine. En la primera parte se describirá la secuencia central de un film para, en la segunda, analizar detenidamente su contenido en relación con la pregunta inicial y finalizar con conclusiones preliminares destinadas a entender el ser-médico-virtuoso como "forma de existencia".

\section{El sueño del examen final}

Escogemos la película del director sueco Ingmar Bergman "Fresas Salvajes" (Smultronstället) no sólo por su sobresaliente calidad artística, sino porque sus intenciones son absolutamente diferentes a las nuestras ${ }^{24-28}$. Así sorteamos posibles reflexiones conceptuales de Bergman sobre ser-médico-virtuoso y con ello entendemos la "bioética de la virtud" como narración de una existencia concreta: penetrar en lo íntimo de una vida humana ${ }^{29}$.

El profesor Isak Borg es un médico de 76 años que en el día de hoy recibirá el título "doctor honoris causa”, máximo premio que el gremio le otorgará por sus cincuenta años de descollante labor profesional en la Catedral de Lund. Viudo, solitario, ordenado y con un hijo médico, siente que la medicina pasó de ser un medio, ganarse el sustento, a un fin, una actividad científica que llenó completamente su existencia. Un sueño desazonador durante la madrugada lo impulsa a viajar en auto, y no en avión, desde Estocolmo, donde va recorriendo diversos lugares que le recuerdan su feliz juventud, primeros años de ejercicio profesional y su frustrado matrimonio. Después de visitar a su anciana madre, lúcida pero impermeable a las emociones, poco antes de llegar a su destino lo asalta otro inquietante sueño.

Es de noche cerrada y la luz de la luna ilumina una casa desconocida y, aunque acerca su rostro a la ventana, no ve a nadie. Golpea con los nudillos pero no se le responde y al apoyar su mano en el marco se lastima su palma con un largo clavo que hay allí. Sorprendido se mira la herida. Se dispone a alejarse cuando alguien lo llama. Es un hombre de mediana edad formalmente vestido que lo invita a entrar: "Adelante, por favor, Profesor Borg". La casa ha cambiado de aspecto y la ventana es, en realidad, una puerta. Ingresa por un extraño pasillo, al final del cual se encuentra una puerta. $\mathrm{Al}$ abrirla se encuentra al interior de una pieza que parece una aula universitaria donde están sentados silenciosamente algunos jóvenes en el estrado. Al otro lado descubre una mesa-pupitre con una pizarra en la pared.

Con gesto autoritario el extraño lo conmina a sentarse y le solicita su "papeleta de examen". Ya no cabe dudas de que se trata de su examen por lo que Isak se la pasa, sin sorprenderse. El examinador comienza a cotejarla con otros papeles mientras se produce un silencio opresivo. Le señala un microscopio que hay enfrente y le pide que diagnostique el tipo de afección que encuentra. Isak se aplica a mirar la placa pero, perplejo, reconoce que no ve nada. "Parece que el microscopio está averiado" le insinúa y el otro verifica por sí mismo: "Está en perfectas condiciones”. "Es que no veo nada" agrega Isak. “ ¿No ve?” ironiza fríamente $y$, tras una pausa, le indica un texto escrito en el pizarrón y le ordena que lo lea. Con voz titubeante deletrea: "Inke tan magrovstak farsin los kret fajne kaserte mjotrom presete”. “Qué quiere decir?" lo interpela. Desconcertado replica: “Pues no lo sé...” “De verdad, no?”. Con más fuerza Isak asevera: "no soy un lingüista... sólo soy un médico". Inflexible el examinador lo confronta: "Sepa que lo que está escrito es el primer deber de un médico ¿Es que no sabe el primer deber?”. Isak apresura la respuesta: "Claro que sí. Pero permítame pensarlo un momento", balbucea. "El primer deber... -vacila- ¡Qué raro! Se me ha olvidado..." Firmemente el otro lo alecciona: “ $¡ E l$ primer deber es pedir perdón!”. Isak sonríe congraciativamente - “Sí, sí!”- y se dirige al público como buscando su aprobación, que impertérrito, lo contempla. El examinador no ceja después de revisar unos papeles: "Otra vez usted es culpable de culpabilidad”. Sin comprender Isak repite: “ $¿$ Culpable de culpabilidad...?”. El asedio continúa sin pausa: "Haré constar que no ha comprendido". "¿Esto es un agravante?" farfulla Isak. La respuesta es terminante: "Desgraciadamente, profesor". Isak queda profundamente perturbado, se sirve agua de una botella derramando parte del contenido y 
contraargumenta: “¿Estoy enfermo del corazón! ¡Y soy un anciano! Creo merecer consideración”. Sin mirarlo el examinador revisa otras carpetas y determina: "Este documento no dice nada del corazón. ¿Quiere interrumpir el examen?”. La respuesta es inmediata: “¡No! ¡Nada de eso!”.

Cambio de escenario en la misma habitación. El examinador enciende una poderosa lámpara como de pabellón quirúrgico y la acerca a una mujer que está sentada en bata de hospital. "Haga el favor de examinar a la paciente y emitir su diagnóstico". Isak se aplica durante un momento y exclama desconcertado: “¡Pero si está muerta!". En esos instantes la paciente abre los ojos y comienza a reír de un modo inquietante, bestial, amenazador. Isak retrocede, asombrado, extrañado y se aproxima al examinador que escribe algo sentado a su mesa. "¿Qué escribe?". "La nota del examen" dictamina fríamente. " $i Y$ qué nota es?". El veredicto es aplastante: "Incompetente". Incrédulo Isak murmura: “ ¿Incompetente?”. Pero la réplica resulta demoledora: "Además se le acusa de otra porción de cosas de menor importancia pero, aún así, gravísimas: insensibilidad, egoísmo, falta de consideración...” “¡No!” gime Isak. "Estas acusaciones han sido hechas por su mujer. ¿Quiere un careo con ella?". "Pero si mi mujer ha muerto hace muchos años". "¿Cree que hablo en broma?”. Los cargos se vuelven más abrumadores cuando los protagonistas abandonan la sala y el escenario del sueño cambia súbita y misteriosamente.

\section{Culpable de culpabilidad}

Un principio metodológico: el relato será analizado como si fuera verdadero aunque no real; usando las palabras de Varga Llosa, "la verdad de las mentiras" ${ }^{30}$ : la trama tiene una referencia verdadera pero no una referencia al mundo real ${ }^{31}$. Freud señaló que hay sueños típicos, entre los que se encuentran los de examen ${ }^{32}$, pero lo decisivo fue que demostró que los sueños tienen un sentido sólo cuando se diferencia el contenido manifiesto del latente ${ }^{33}$. El manifiesto acaba de ser narrado y ahora se necesita entender el contenido latente: encubierto, distorsionado y fuente del sueño por provenir directamente del inconsciente; por medio de la interpretación -método hermenéutico-, se busca detrás de las imágenes lo oculto. El primer paso, previo al interpretar, necesita considerar su trasfondo: la biografía de Isak y los restos diurnos.

Tres hechos resaltan en la biografía de Isak: la progresiva y absorbente dedicación a su profesión como investigador después de haber ejercido como médico tratante, el intenso compromiso emocional con sus investigaciones y el altísimo rendimiento conseguido tras años de duro trabajo. Fruto de sus descubrimientos el gremio médico decidió condecorarlo en una ceremonia solemne que posee un doble atributo: reconocimiento aunque también despedida. Se desconoce si esta dedicación ha perturbado su vida personal, empero lleva una existencia retirada, solitaria, apartada.

Hay tres situaciones que constituyen restos diurnos (Tagesreste) los acontecimientos del día que desencadenaron el proceso onírico ${ }^{34}$. Por un lado, el día de hoy es el gran evento; condecoración seguramente hace tiempo anhelada, se concretará en unas pocas horas y en cuanto máximo premio representa una prueba irrefutable, documento indesmentible de su sobresaliente calidad profesional. Por otro, surge algo imprevisto: sueña de madrugada algo desazonador que parece impulsarlo a viajar en auto en lugar de avión para visitar lugares de su adolescencia; vale decir, retarda el tiempo en lugar de apresurar su arribo a su destino último, cobijándose en su juventud. Finalmente, visita a su madre -regresión extrema- como si antes de adueñarse del galardón requiriera un ajuste de cuentas con su infancia; esto es, el futuro -trofeo honorífico- necesita del pasado revisar su niñez.

El sueño exhibe una secuencia, que puede o no comprender una relación causal: la entrada, el examen mismo y el desenlace. La entrada: solicitada por Isak aunque la petición contiene algo enigmático: nadie lo espera, debe insistir con fuerza, un extraño descuido lo lleva a autoinfligirse una herida en la palma de la mano y, curiosamente, el motivo y finalidad de su petición o no los tiene conscientes o no los expresa. Pero la ambigüedad la resuelve un extraño: formal, distante, lo invita a ingresar como si lo esperara, es él quien sabe de qué se trata y desde el comienzo dictamina las reglas.

El examen: envuelto en una atmósfera progresiva y crecientemente inhóspita hasta tornarse casi en intolerable. El hecho de ser sometido a un interrogatorio no es cuestionado como tampoco el examinador. Contrariamente, Isak también sabe y conoce su destino: se trata de su prueba decisiva y final; por ello va premunido de su "papeleta de 
examen". Además el examinador, de menor edad, es enigmático, impersonal, está en posesión de todos los antecedentes tanto académicos como privados que coteja con una objetividad basada en hechos irrefutables, no establece ningún vínculo que denote empatía o comprensión ante debilidades, insuficiencias o yerros.

Los rendimientos son incomprensiblemente catastróficos desde el inicio: descalabros repetidos que no mejoran sino se acumulan ominosamente. Sus fracasos abarcan el ámbito profesional y el íntimo; aún más, son fracasos que ya había cometido "otra vez", como se le enfatiza. Profesionalmente falla en diagnosticar una placa al microscopio, no sabe descifrar lo escrito ni recordar lo enseñado como primer deber del médico, no capta la diferencia entre la vida y la muerte de una paciente, no se percata de las propias insuficiencias o las achaca a causas externas. Hay una contradicción incuestionable: sus fracasos en este examen son incongruentes con sus éxitos profesionales. ¿Serán errores técnicos? Pareciera que no, todo lo contrario. No sabe "ver", no sabe "leer", no sabe sus "deberes", no sabe de sus propios "agravantes", no sabe distinguir "lo vivo de lo muerto": es su propia persona la que está en cuestión, es la ceguera o agnosia de sí -y de los otros- la que se le está reprochando.

Por ello el primer veredicto -"culpable de culpabilidad"- apunta a su ser y, con ello, a su manera íntima de vivir su profesión. Los triunfos y galardones médicos esconden insuficiencias humanas pero especialmente morales, que ha conseguido ignorar y ocultar ante sí-mismo hasta ahora. El examinador no tolera más el engaño y lo desnuda con una ferocidad desconocida para él: la fama, la vanidad, la prepotencia, la arrogancia conducen a sobresalir, triunfar pero a costa de violentar, degradar, humillar personas.

El desenlace es brutal: incompetente. Isak no entiende la incompetencia porque la supone técnica, pero es ética y para con el otro en este caso, su paciente y su esposa, o lo que ellas representan: los afectos, el amor, la entrega, el cuidado, la preocupación. Su réplica de que están muertas -la esposa hace años- es su último subterfugio: se le apremia a que se enfrente por vez primera a su vida emocional y moral sepultadas. Isak ha presumido de una inocencia inicial pero la revelación progresiva ha derrotado su conciencia presuntuosa, ha señalado la acción de deseos turbios cuando alardeaba que estaba investigando científicamente, ha mostrado ansias voraces que lo condicionaban y dirigían de manera soterrada. Ha llegado el momento del careo final consigo simbolizado en las imputaciones de su esposa.

\section{"La sabiduría sólo se alcanza a través del sufrimiento"}

Es lo que dice el coro de Agamenón de Esquilo: pathei-mathos ${ }^{35,36}$, es lo que le insinúa el examinador a Isak. No es casualidad que sea a través de un sueño y justo el día de la culminación y término de la profesión: su verdad moral la tolera sólo indirecta y simbólicamente.

1. ¿Quién es el examinador? Su propia y severa conciencia que le revela lo que ha sabido siempre pero que ha olvidado producto de la presunción (hybris) de sus éxitos y premios, que no supo "pedir perdón" - tener com-pasión.

2. ¿Qué le dice del sentido de ser merecedor del "doctor honoris causa"? Le recuerda que su período de iniciación de médico se selló con un juramento solemne en que se comprometió a guardar un conjunto de valores y que hoy día debe responsabilizarse -con veracidad total- de si ha cumplido a cabalidad con los deberes de esa promesa solemne. No se trata de si fue diligente con las formalidades exigidas jurídicamente por la ley, sino de si guardó fidelidad a las reglas moralesexistenciales inherentes al juramento.

3. ¿Cuáles son los deberes que prometió cumplir? Aceptó que la medicina es una profesión, un compromiso y una responsabilidad. Como profesional, debió ser una persona profesa, un consagrado, como lo confesó públicamente en el momento de jurar, no simplemente una persona dedicada a ejecutar una ocupación u oficio; debió ofrendarse y ponerse al servicio y cuidado de sus pacientes. Como comprometido, tenía que llevar a cabo una entrega completa, mantenida y sostenida con aquello que prometió, con la alianza que hizo en el momento del juramento inicial; therapeía, como le enseñaron sus maestros: servicio y culto a los dolientes. Como responsable, necesitaba responder, hacerse cargo del pacto solemnemente asumido; empeñarse, cumplir y prometerse a sí y al otro, más allá de la responsabilidad de jure y mandatos sociales punitivos.

4. ¿Cuál es su culpabilidad? No se trató de fa- 
llos como la ignorancia, impericia, imprudencia o negligencia, que tienen que ver con las virtudes dianoéticas o técnicas, según Aristóteles ${ }^{37}$, sino con los fines extrínsecos de la profesión, como buscar la fama y prestigio desmesurados. Pero especialmente con algo más profundo, con el "bien de sí-mismo", con la intención, convicción y desarrollo de sus potencialidades: qué clase de médico tenía que haber sido para haber tenido derecho a poner las manos sobre otras vidas humanas. Para ello debió haber conservado el recogimiento y la serenidad, esto es, la sabiduría moral o prudencia (phrónesis), actitud que lo habría legitimado para curar enfermos y sus dolencias.

\section{Téleios iatrós}

A) Casi todos los doctores experimentamos similares sueños de examen final, lo que indica que obedecen a vivencias indelebles cargadas del pathos inherente a nuestro aprendizaje: haber logrado ser médico es determinante en forjar el “carácter”. Ética (êthos) significa carácter: hábitos o actitudes indelebles que nos constituyen y guían, pero también apremian, exigen y reclaman justificaciones durante toda la vida.

B) La medicina es un modo de vida, el bíos iatrikós, pero se es propiamente médico virtuoso cuando, junto a las virtudes dianoéticas o intelectuales, se imbrican las virtudes éticas. Siguiendo a Aristóteles, de estas últimas no cualesquiera: sólo las superlativas, que poseen el máximo grado, las óptimas ${ }^{4}$. Es decir, el médico deviene "perfecto" cuando a la virtuosidad técnica se agrega la virtud moral, transformándose ésta en su segunda naturaleza, en un modo de vida.

C) Aristóteles enfatiza que sólo realizando acciones [virtuosas] uno se hace [virtuoso] "y sin hacerlas ninguno tiene la menor posibilidad de llegar a ser bueno", y los que sólo se refugian en la teoría se engañan y creen "poder llegar así a ser hombres cabales" ${ }^{\prime 37}$. Por ello la excelencia (areté) es "un hábito por el cual el hombre [médico] se hace bueno y por el cual ejecuta bien su función propia”, es un êthos, carácter o actitud fundamental.

D) Isak Borg optó por aquello que Weber denominó ética de la responsabilidad ${ }^{38}$, claramente teleológica, la que decide en función de las consecuencias de los actos y cuya estructura se centra en los medios y fines: que un paciente sea portador de una bacteria precisa es lo decisivo porque así se aplicará al antibiótico específico. Pero mini- mizó la de la convicción (Gessinungsethik), la de principios internos, que valen en toda situación y conforman el êthos médico, su habitud de obrar según el bien-en-sí o "finalidad intrínseca". Le faltó prudencia (phrónesis): obrar teniendo en cuenta las dos posturas éticas fundamentales -el justo término medio (Aristóteles)- y de oscilar según las circunstancias.

E) El examen final de Isak Borg muestra el "mal radical" de Kant inherente a nuestra condición: jamás podremos alcanzar a cabalidad ser sujetos moralmente virtuosos o excelentes (areté) ${ }^{39}$. Pero simultáneamente lo que Séneca denominó "artífice de su propia vida" 40 .

F) Este análisis ético merecería una interpretación del sentido emocional y existencial referido al logro del triunfo final: superación definitiva del padre como máxima autoridad, obtención del cariño inagotable de la madre, formación del narcisismo básico indispensable para la identidad personal; pero siempre persistirá culpa, rabia, envidia, celos y duelo ${ }^{27,28}$. Esto trasciende las metas del presente trabajo.

\section{Referencias}

1. García Gual C, editor. Tratados hipocráticos. Madrid: Gredos, 1983.

2. Laín Entralgo P. La medicina hipocrática. Madrid: Revista de Occidente, 1970.

3. Miles SH. The Hippocratic oath and the ethics in medicine. New York: Oxford University Press, 2004.

4. Aristóteles. Metafísica de Aristóteles. 2 tomos. Madrid: Gredos, 1970.

5. Deichgräber K. Medicus gratiosus. Untersuchungen zu einem griechischen Artzbid. Mit einem Anhang "Testamentum Hippocratis" und Rhazes "De indulgencia medici". Mainz: Akademie der Wissenschaften und der Literatur, 1970.

6. Knottnerus JA, Buntinx F, eds. The evidence base of clinical diagnosis. Theory and methods of diagnostic research. 2nd edition. New York: Wiley-Blackwell, 2008.

7. Figueroa G. ¿Al fin una medicina humanista? Rev Med Chile 1999; 127: 94-100.

8. Gracia D. Contribución de las humanidades médicas a la formación del médico. Humanitas. Humanidades médicas. Tema del mes on-line $\mathrm{n}^{\circ} 1$, marzo de 2006.

9. Hanson MJ, Callahan D, editors. The goals of medicine: the forgotten issues in health care reform. Washington: Georgetown University Press, 1999.

10. Foucault M. Naissance de la biopolitique. Cours au Collé- 
ge de France (1978-1979). Paris: Seuil/Gallimard, 2004.

11. Callahan D. False hopes: why America's quest for perfect health is a recipe for failure. New York: Simon and Schuster, 1998.

12. Gracia D. Por una asistencia médica más humana. En: Como arqueros al blanco. Estudios de bioética. Madrid: Triacastela, 2004. p. 93-103.

13. Pellegrino ED. Towards a virtue-based normative ethics for the health professions. Kenn Inst Ethics J 1995: 253 7.

14. MacIntyre A. After virtue. 2nd edition. Indiana: University of Notre Dame Press, 1984.

15. Heidegger M. Wissenschaft und Besinnung. En: Vorträge und Aufsätze. 5. Auflage. Pfullingen: Neske 1967. p. 4166.

16. Rorty R. Essays on Heidegger and others. Cambridge: Cambridge University Press, 1991.

17. Heidegger M. Der Ursprung des Kunstwerkes. En: Holzwege. Gesamtausgabe 5. Frankfurt: Klostermann 1984. p. 7-68.

18. Lesoeurs G. La santé a l'écran: medicine et patients au cinema. Paris: Tetraedre, 2003.

19. Battle Caminal J. Medicina y cine: encuentros, tribulaciones y cortocircuitos entre cine y medicina. Barcelona: Edipharma, 1998.

20. Muñoz S, Gracia D. Médicos en el cine. Dilemas bioéticos: sentimientos, razones y deberes. Madrid: Editorial Complutense, 2006.

21. Gabbard GO, Gabbard K. Psychiatry and the cinema. 2nd edition. Washington: American Psychoatric Press, 1999.

22. Pellegrino ED, Thomasma DC. The virtues in medical practice. New York: Oxford University Press, 1983.

23. Drane JF. Becoming a good doctor: place of virtue and carácter in medical ethics. Kansas: Sheed and Ward, 1988.

24. Bergman I. Fresas salvajes. DVD/Vértice Cine S.L.U, 2003.

25. Bergman I. Wilde Erdbeeren und andere Filmerzählungen. München: Hanser. 1973.
26. Bergman I. Linterna mágica. Barcelona: Tusquets. 1988.

27. Figueroa G. Sueños y existencia: el sueño en el arte cinematográfico. En: Ferrer S. Interpretación de los sueños. Santiago: Mediterráneo, 2013. p. 131-48.

28. Figueroa G. Triunfo, culpa y muerte reconsiderados: la interpretación de un sueño en "Fresas salvajes" de Ingmar Bergman. Rev Chil Neuro-Psiquiat 2002; 40: 210-37.

29. Hunter KM, editor. Doctor's stories: the narrative structure of medical knowledge. Princeton: Princeton University Press 1991.

30. Vargas Llosa M. La verdad de las mentiras. Madrid: Punto de lectura, 2007.

31. Ricoeur P. Temps et récit. La configuration dans le récit de fiction. Paris: Éditions du Seuil 1983.

32. Freud S. Die Traumdeutung. Gesammelte Werke II/III. Frankfurt: Fischer 1900. p. 1-642.

33. Freud S. Die Handhabung der Traumdeutung in der Psychoanalyse. Gesammelte Werke VIII Frankfurt: Fischer 1912; 349-57.

34. Figueroa G. El giro de la "Interpretación de los sueños" de Freud y la disidencia de Jung. En: Ferrer S. Interpretación de los sueños. Santiago: Mediterráneo, 2013 p. 111-30.

35. Esquilo. Agamenón. En: Tragedias. Madrid: Gredos, 2000. p. 101-72.

36. Figueroa G. La bioética actual: las interrogantes de Heidegger. Rev Med Chile 2011; 139: 1377-82.

37. Aristóteles. Ética a Nicómaco. Madrid: Centro de Estudios Constitucionales, 1985.

38. Weber M. Politik als Beruf, Wissenschaft als Beruf. Berlín: Dunker \& Humboldt, 1965.

39. Kant I. Die Religion innerhalb der Grenzen der blossen Vernunft. En: Kant Werke. Band 7. Schriften zur Ethik und Religionsphilosophie. Darmstadt: Wissenschaftliche Buchgesellschaft, 1968. p. 645-865.

40. Foucault M. L'herméneutique du sujet. Cours au Collège de France 1981-1982. París: Seuil/Gallimard, 2001. 